\title{
DEVELOPMENT STRATEGIES OF PURE WAFER FOUNDRIES USING AHP
}

\author{
Mei-Chen Lo ${ }^{\mathrm{a}, 1}$, Chun-Yen Chang ${ }^{\mathrm{b}}$, Gwo-Hshiung Tzeng ${ }^{\mathrm{a}, \mathrm{c}}$, Fang-Mei Tseng ${ }^{\mathrm{d}}$ \\ ${ }^{\mathbf{a}}$ Institute of Technology Management, ${ }^{\mathbf{b}}$ Institute of Electronics Engineering \\ National Chiao Tung University, 1001, University Road, Hsin-Chu 300, Taiwan \\ ${ }^{`}$ Kainan University, No. 1 Kainan Rd., Lu-jhu, Taoyuan 338, Taiwan \\ dDepartment of International Business, Yuan Ze University, \\ 135 Yuan-Tung RD., Chung-Li, Taoyuan 320, Taiwan \\ cyc@mail.nctu.edu.tw, ghtzeng@cc.nctu.edu.tw, mjlo.mt90g@nctu.edu.tw, fmtseg@saturn.yzu.edu.tw
}

Keywords: Analytic Hierarchy Process (AHP), Multiple Attribute Decision Making (MADM), wafer foundry, semiconductor

Summary: The semiconductor dedicated foundry industry was first operated in 1987. The pure-play foundry in real production, in turn, fostered the booming fabless IC segment, as well as the burgeoning design services industry. This study adopted the empirical cases to analyze the important attributes for operating an efficient wafer foundry fabrication (Fab). The proposed approach uses an Analytic Hierarchy Process (AHP) to assign weights, enabling internal employees, varied groups and the leaders to identify generic process elements that are relevant to the current business flow.

\section{Introduction}

The wafer foundry is a fragmented business, subjected to continuous technology innovation. Their services enable semiconductor fabs to produce at lower prices with high quality. As the semiconductor industry's process technology leaders, wafer foundry companies have frequently spearheaded advancements by skillfully leveraging its own R\&D resources and the world-class expertise of its material suppliers, IC designers or service alliance partners. They continue their market leadership by steadily increasing its capital spending and by outperforming all other market competitors.

The characteristics of foundry business has been described and the factors of driving pure play wafer foundry business which include manufacturing competence and development strategies, partnership with clients, production/customer oriented business strategies, technology and global marketing are discussed. Then, we focus on collaborative relationships with customers, suppliers and technology partners and unerring focus on providing services, that has drawn the market to the company and enable a customer to achieve success to earn customers' trust in all facets of company's relationships. These efforts have laid a foundation for win-win partnerships that endure both over time and through the most challenging of environments.

\section{Foundry Business Strategy}

The evolution of advanced IC technology over the past decade has been so rapid that it has changed the way that all companies do business. Demands for faster design cycles and faster time-to-market have increased. Demands for higher speeds and product quality have increased as well. These are main reasons among the many others that the companies turn to foundry as their manufacturing partner.

\subsection{The Evolution of Semiconductor Manufacturing}

\footnotetext{
${ }^{1}$ Corresponding author.
} 
The semiconductor foundry business has lead Taiwan electronic industry prosperity. The effect can even affect to its supply chain and traditional industry in some certain degree. As we know the foundry business is focus on production phase (Chang et al., 2003), therefore, continuously pursuit process technology in leading edge could be the only way as we use to think about the business strategies to be suggested. For past decade, foundry business has prominent profit on market performance. Although business cycle impacts the utilization of wafer fab, still, the trend of foundry business has already proved from its historical record. The industrial vertical integration can move to be vertical dis-integration and it makes the relationship among the industry to be closer. A linear development trend shows the market demand have continued to drive higher technology and low cost. This study assesses the manufacturing competence and development strategies for pure wafer foundry business if the plans for continuous expansion can be made. Therefore, the basic business model, which is somewhat different from the industry norm, and the companies were confident with a winning strategy of invention, innovation and implementation for going forward.

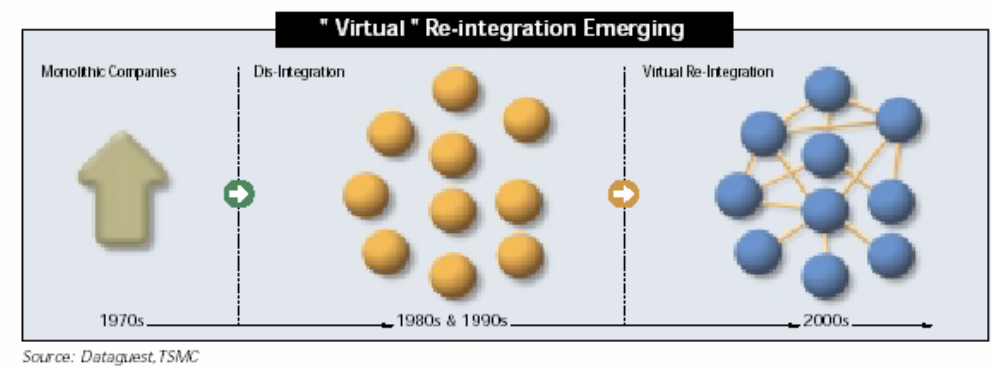

Figure 1 Integration to dis-integration model

Accelerated electronics consumption and an increasing proportion of IC content in all products have created a demand-side market pull. Working under this dynamic tension, the industry evolved from an integrated business model to a dis-aggregated business model. The IC industry's history could be described as an innovation business process of arousing technological advances and IC roadmaps.

The semiconductor dedicated foundry industry was first operated and introduce this evolution of the pure-play foundry in real production in 1987. This model, in turn, fostered the booming fabless IC segment, as well as the burgeoning design services industry. Figure 1 and 2 illustrate this evolution.

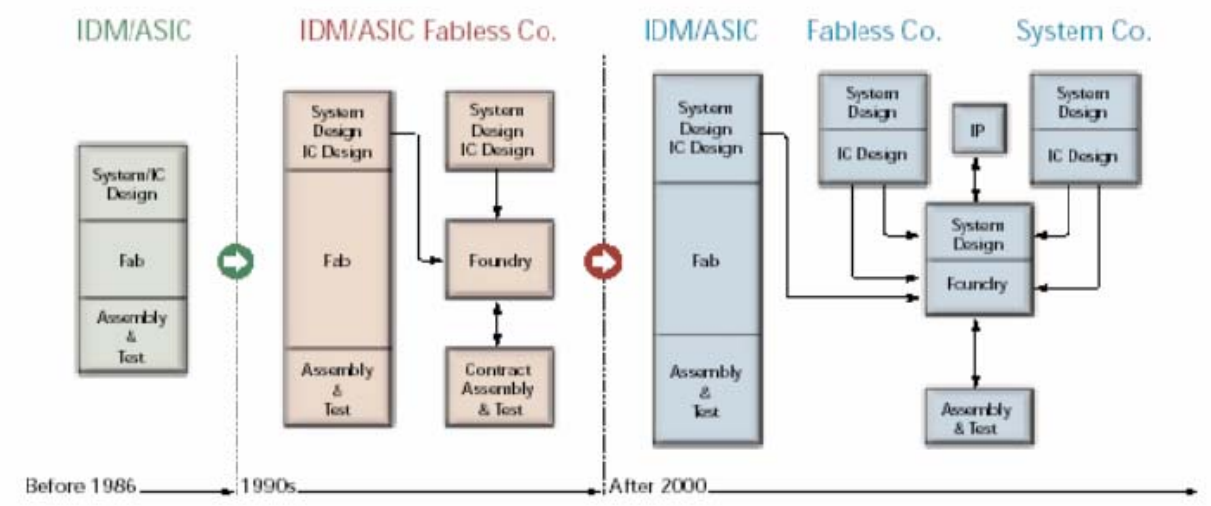

Figure 2 Dis-integration of the IC Industry

\subsection{Major Wafer Foundry Players}

Taiwan's foundries have made significant investments. Taiwan semiconductor manufacturing company (TSMC) and United microelectronic company (UMC) are the most famous major players in this field. 


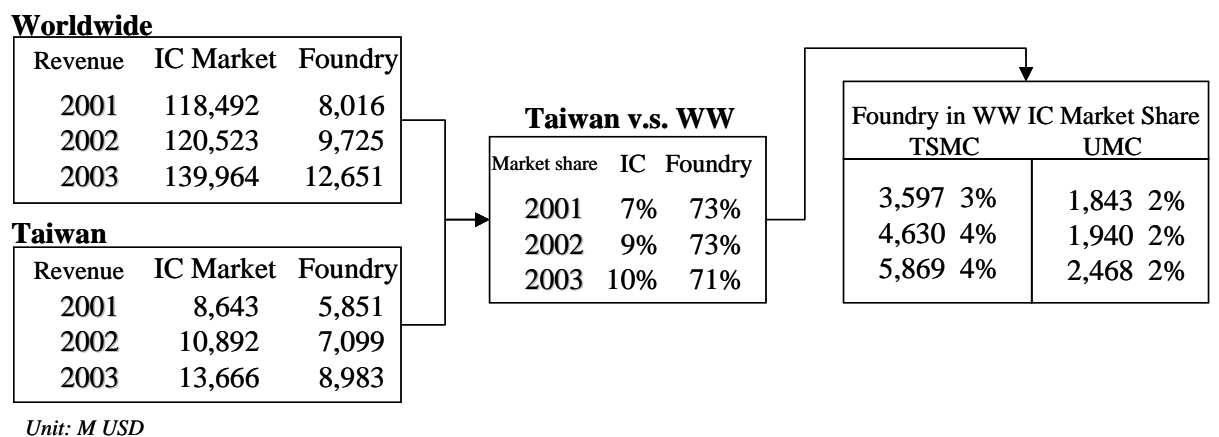

Figure 1. Market share of Taiwan v.s. Worldwide

Data source: IC Insights; IEK-ITRI, Taiwan. April 2004

TSMC posted annual sales of \$5.9 billion (\$US) in 2003 and currently employs over 15,000 people worldwide and maintains account service offices in Taiwan, North America, Europe and Japan. UMC posted annual sales of $\$ 2.5$ billion (\$US) in 2003 and employs over 9,500 people worldwide and has offices in Taiwan, Japan, Singapore, Europe, and the United States. Both serve and support their customer's manufacturing needs, not only as the foundry technology leader and industry leader; but also are a world-leading semiconductor foundry, specializing in the contract manufacturing of customer designed ICs for high performance semiconductor applications. Besides, UMC since entering the pureplay foundry industry in 1995, has been the sector's fastest growing company. Its position as the foundry industry technology leader has been a major contributing factor to its rapid growth. Both foundry companies deliver the cutting-edge foundry technologies that enable sophisticated system-on-chip (SOC) designs, including 0.13um copper/low k, embedded DRAM, and mixed signal/RFCMOS.

\subsection{The Characteristics of Pure Play Foundry Business}

The characteristics of pure play foundry business: (1) integrity with customers, vendors and employees with telling the truth and maintaining an objective, consistent, and impartial attitude; (2) maintaining a consistent focus on core business, IC Foundry must focus on their business, which is dedicated IC foundry, and not distract themselves with other pursuits; (3) Globalization business, not limit themselves to domestic market or any specific geographical region. It is important to recognize that the semiconductor business has no national boundaries, and that to be competitive anywhere foundry business must be competitive in the whole world; (4) Unceasing innovation is the wellspring of the growth. It is vital to all sectors of foundry business, from strategic planning to marketing, management, technology and production.

Foundry service have contained: (1) a complete listing of available industry-standard technologies; (2) several unique wafer fab technologies are available with minimal or no design support. In general, access to these technologies is determined by a custom of customer. Typical decision factors are wafer volume requirement, the technology required, and overall business opportunity; (3) can provide a range of products, support, and services from untested wafers to packaged and tested modules; (4) have committed capacity available for the foundry technologies and reserved capacity for foundry customers; (5) customer purchase capacity, there are two ways for a customer to gain access to the capacity: a). place a purchase order specifying a specific volume over a specific time period for a given product. The company will acknowledge and commit to the customer requirements based on their ability to meet the customers demand; b). customer can sign a reserved capacity contract that guarantees a level of capacity; (6) yields and reliability targets are competitive with other foundry providers in the industry. Targets for customer-specific designs are defined during the early production runs, and are based on the actual manufacturing yield results of the customer's wafers. Typically, the yields are determined by the technology chosen, the complexity of the customer design, the test coverage, and the size of the chip; (7) packaging services: have a vast array of packaging options (have both the company's own packaging and third-party source capability); (8) provide engineering, quality, and supply chain data to help run a business (refer to the websites of www.tsmc.com and www.umc.com). 


\subsection{The Factors of Driving Pure Play Wafer Foundry Business}

The factors of driving pure play wafer foundry business are viewed according to four aspects which are production, marketing, technology and activities (Figure 1). Then the brief discussion of the issues have been highlighted as below:

Manufacturing competence and development strategies based on top quality manufacturing services (Su et al., 2005) which with constant monitoring and improving manufacturing practices, and it is able to deliver quality assured shipments in a timely manner to its customer. For enhancing company's ability to serve customers by operating, expanding and developing facilities; Culture to urge the employees to demonstrate the way to perform their effort through the work attitude is essential. Besides, the advanced automation, mature defect density, and competitive cycle times along with an aggressive capacity expansion plan enable foundry companies to be the foundry of choice for customers' manufacturing needs. Professional foundry service, the customers will earn the competitive advantages with the effective reduction of the total system cost and time-to-market.

Partnership with Clients: Business strategies are characterized by dynamic complexity, tacit knowledge factors, feedback effects over time, and un-structure (Sterman, 2001). Collaboration, confidence and closeness to customers are the keys to successful partnership. In looking out upon a fast changing industrial environment and new opportunities, corporate vision can be articulated more than once depending on the position or affect force in the industry. In the situation of foundry that vision, customer collaboration is key. But collaboration and mutual success occur only when there are foundry-related services available to bring vision to reality. To foundries, partnership means openly sharing roadmaps and R\&D resources, proactive mutual support that results in mutual success, and long-term relationships that are built on trust and respect. Foundries have secured the trust of customers by delivering on their service commitment during business cycling. Implementing well-rounded program management services, customer-oriented global support, and proactive service integration.

Production Oriented and Customer Oriented company provides a full range of integrated IC foundry services that fulfill the increasing variety of customer needs on a worldwide basis: (1) access to advanced technologies and processes; (2) supply chain information management services; (3) product planning support; (4) production and delivery consistency; (5) production volume control; (6) quality control, (7) responsiveness; and (8) stability in customer/manufacturer relations.

This is all made possible through a unique customer-first business model called "virtual fab" (Hsieh, et al., 2002) that combines customer oriented business strategy with its pioneering dedicated IC foundry experience, management's commitment to customer satisfaction, and a systematic approach to responding immediately to customers' needs.

Technology: Foundries have always been aggressive in pursuing new inventions and overall technology advancement. Aggressive Research and development (R\&D) spending year after year is a testament to the commitment to technology leadership. R\&D group is committed to pushing the forefront of technology and providing the latest market-driven, customer-focused and cost effective integrated circuitry manufacturing solutions. With R\&D team's efforts, it provides multiple options to accommodate a wide variety of designs and applications including computer, communication, and consumer products.

In addition, cooperating with several Integrated Device Manufacturers (IDMs) in the process development stage to jointly develop tailored technologies. This will help shorten product development and manufacturing cycle times.

The way of reducing the time to market is one of the most frequently mentioned in the semiconductor industry today. Not only simply a solution on a matter of proving the best process technologies for customers. Rather, provide the best process technologies and related foundry services, integrated to meet the unique product and business requirement of each customer on an individual basis. 
Global Marketing: Foundries often extends its services beyond corporate boundaries to coordinate with vendors to provide technology leadership and to resolve issues that occur along a customer's supply chain. Building a customer-oriented global Support is an important strategy to Taiwan's pure-play foundries; it has turned to strategic market and technology leaders to drive leading-edge processes. Customer products have been the essential drivers pushing advanced technology. The company's technology leadership is recognized by the fact that received more semiconductor patents than any other company.

The customer enjoys a huge business advantage, while the global support from foundries contributes to infrastructure necessary for sustaining aggressive growth. Effective global support for a multi-national customer depends on an innovative cross-regional support plan. Also, the cross-regional support provides 24-hour communications that results in improved technical and logistical support in terms of timeliness and thoroughness.

\section{Methodology}

In the literature, most scholars have employed an all-phase efficiency index to assess the business performance of fab operation and business strategies, they set up the weight for each criteria of hierarchy structure. Therefore, to assist the study enable to illustrate the performance efficiency, the proposed approach uses an AHP to assign weights, enabling internal employees, varied groups and the leaders to identify generic process elements that are relevant to the current business flow.

\subsection{AHP}

The AHP was first proposed by Thomas L. Saaty in 1980 (Saaty, 1980). For years it has been used in several areas of social management sciences, integrates opinion and evaluation of experts and devises the complex decision making system into a simple element hierarchy system. Application of AHP for group decision-making environments involves defining a common hierarchy of criteria, specifying pair-wise comparisons by criteria of the group and aggregating those pair-wise comparisons for the entire group. Saaty used the principal eigenvector of the comparison matrix to find the comparative weights among the criteria of the hierarchy systems. If we wish to compare a set of $n$ criteria pair-wise according to their relative importance (weights), then denote the criteria by $C_{1}, C_{2}, \ldots, C_{n}$ and their weights by $w_{1}, w_{2}, \ldots, w_{n}$. If $w=\left(w_{1}, w_{2}, \ldots, w_{n}\right)^{T}$ is given, the pair-wise comparisons may be represented by matrix $\mathrm{A}$ of the following formulation:

$$
\left(A-\lambda_{\max } I\right) w=0
$$

Eq.(1) denotes that $A$ is the positive reciprocal matrix of pair-wise comparison values derived by intuitive judgment for ranking order. In order to derive the priority eigenvector, we must find the eigenvector w with respective $\lambda_{\max }$ which satisfies $A w=\lambda_{\max } w$. Saaty suggested the consistency index (C.I. $=\frac{\lambda_{\max }-n}{n-1}$ ) to test the consistency of the intuitive judgment. In general, a value of C.I. which less than 0.1 are satisfactory.

\subsection{Building hierarchy system}

A decision-maker bases judgment on knowledge and experience, and then makes decisions accordingly. The fab operation stresses the critical role in effective implementation, therefore, fab directors are faced with decision environments and problems in wafer moves that are complex, where there are many interrelated problems. Therefore, brainstorming to share ideas and insights often leads to a more complete representation and understanding of the issues. The brainstorming approach is a common way to aggregate ideas for decision-making. Then, the AHP allows group decision-making, where group members can use their experience, values and knowledge to break down a problem into a hierarchy and solve it by the AHP procedure. The model consists of three steps: (1) situation description from the objects' study; (2) construction the correlation tree structure of multiple evaluation phases and evaluation 
criterions; (3) carrying out questionnaire design, the investigation and analysis through experts' brainstorming and discussion. AHP is essentially a data-weighting technique and its framework is utilized to formalize principles by which database semantics can be identified and compared with the real world.

This study incorporates the four-aspect representation of measuring manufacturing competence and development strategies of pure wafer foundries. Figure 1 shows an evaluation hierarchy structure and its various levels as it was presented in a questionnaire. This aims at the operation production, marketing, technology and Management Activities, which are the four phases to determine the participant cognition of relative importance (weight).

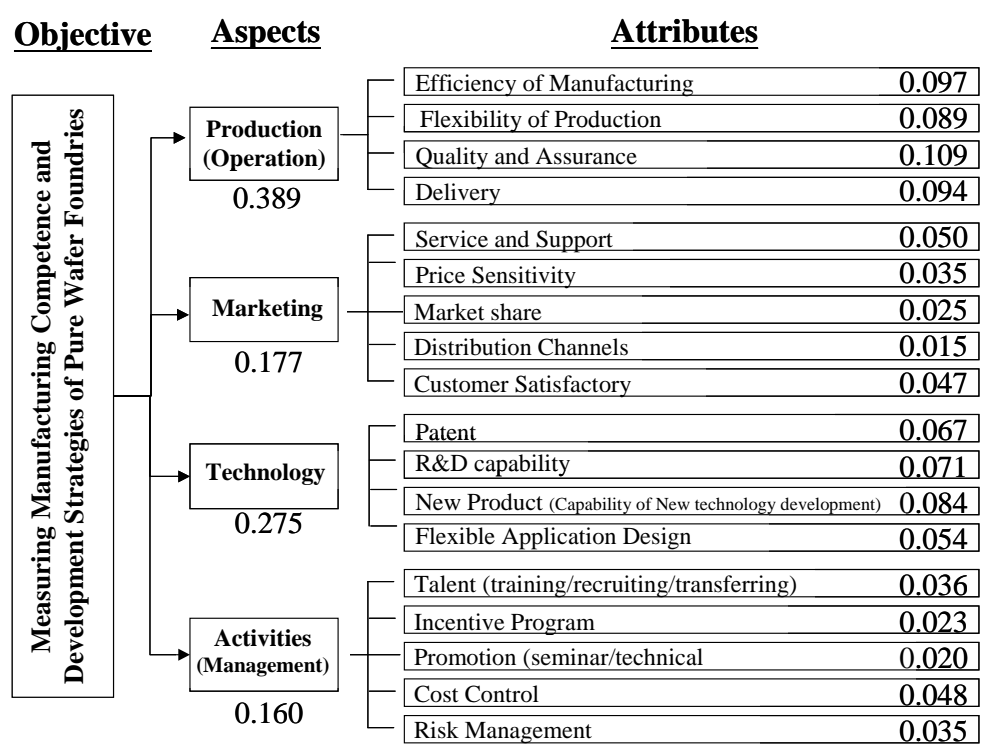

Figure 1. Hierarchy structure with weights

In order to aggregate the synthetic performance value of all possible alternatives/strategies in multiple attribute decision-making (MADM) problems, we ought firstly to determine the required information about the relative importance/weight of each criterion/attribute.

\subsection{Result analysis}

Wafer foundry is concentrating on wafer manufacturing business. The production orientation strategies can be taken mostly to achieve its high yield rate and tool utilization on each fabrication. Consequently, the result reveals there are a perfect consistency (Table 1) on giving the importance of manufacturing competence and development strategies.

Table 1. The Weight by Aspects

\begin{tabular}{lcccc}
\hline & Production $\left[w_{1}\right]$ & Marketing $\left[w_{2}\right]$ & Technology $\left[w_{3}\right]$ & Activities $\left[w_{4}\right]$ \\
\hline Fab Operation & $0.38(1)$ & $0.19(3)$ & $0.28(2)$ & $0.15(4)$ \\
Operation Support & $0.37(1)$ & $0.18(3)$ & $0.28(2)$ & $0.17(4)$ \\
Marketing & $0.42(1)$ & $0.16(3)$ & $0.26(2)$ & $0.16(3)$ \\
Top Manager & $0.38(1)$ & $0.19(3)$ & $0.27(2)$ & $0.17(4)$ \\
\hline Overall Weights & $0.39(1)$ & $0.18(3)$ & $0.27(2)$ & $0.16(4)$ \\
\hline
\end{tabular}

The sequences of importance are production, technology, marketing and activities (management). Due to the characteristics of wafer foundry business, its major content on manufacturing work have led all the activities and resources to be projected. It also implies the necessity of the goal setting for enterprise is 
important and to be made clear enough to operate a wafer fab while doing a successful wafer foundry business. From the viewpoint of performance measure (Table 2), it illustrates marketing and technology have slightly change on its satisfaction as current view of business situation. It also can happen that the good/bad timing of business cycling impact directly on the focus actions on business strategies. When the cycling goes up, companies more focused on market exploring for reaching higher sales target. Then, the down time could change the way of seeking opportunities to new technology innovation and development.

Table 2. The Performance Measure by Aspects

\begin{tabular}{rcccc}
\hline & Production $\left[w_{1}\right]$ & Marketing $\left[w_{2}\right]$ & Technology $\left[w_{3}\right]$ & Activities $\left[w_{4}\right]$ \\
\hline Fab Operation & $8.09(1)$ & $7.83(2)$ & $6.21(3)$ & $2.95(4)$ \\
Operation Support & $8.09(1)$ & $7.47(3)$ & $7.72(2)$ & $5.92(4)$ \\
Marketing & $3.77(1)$ & $1.43(3)$ & $2.50(2)$ & $1.14(4)$ \\
Top Manager & $2.03(1)$ & $1.92(2)$ & $1.00(4)$ & $1.07(3)$ \\
\hline Overall Weights & $21.98(1)$ & $18.65(2)$ & $17.42(3)$ & $11.08(4)$ \\
\hline
\end{tabular}

Table 1 and Table 2 demonstrate the consistency on production when viewing from four different fields. Also, the ranking supports a concept of the four major functions in a company regard different drive force of pushing the growth of company.

\section{Discussion and Suggestions}

\subsection{Discussion}

The different functions fab operation, operation support, marketing and top management have its own priority while seeking the way of improvement on manufacturing competence and development strategies of pure wafer foundries.

Table 3 Top Five of Criteria on Improving Strategies

\begin{tabular}{|c|c|c|c|c|c|}
\hline Top 5 & Fab Operation & Operation Support & Marketing & Top Manager & Overall Focus \\
\hline 1 & \begin{tabular}{|l|} 
Efficiency of \\
Manufacturing
\end{tabular} & Service and support & $\begin{array}{l}\text { Flexibility of } \\
\text { production }\end{array}$ & $\begin{array}{l}\text { Quality and } \\
\text { assurance }\end{array}$ & \begin{tabular}{|l|} 
Efficiency of \\
manufacturing
\end{tabular} \\
\hline 2 & Service and Support & R\&D capability & New product & Price sensitivity & Service and support \\
\hline 3 & Delivery & Delivery & $\begin{array}{l}\text { Efficiency of } \\
\text { manufacturing }\end{array}$ & Delivery & Delivery \\
\hline 4 & R\&D capability & $\begin{array}{l}\text { Quality and } \\
\text { assurance }\end{array}$ & $\begin{array}{l}\text { Quality and } \\
\text { assurance }\end{array}$ & New product & $\begin{array}{l}\text { Quality and } \\
\text { assurance }\end{array}$ \\
\hline 5 & Market share & New product & $\begin{array}{l}\text { Flexible application } \\
\text { design }\end{array}$ & $\begin{array}{l}\text { Service and support } \\
\text { \& customer } \\
\text { satisfactory }\end{array}$ & New Product \\
\hline
\end{tabular}

The overall focus indicates that the top five improving strategies among the evaluated criteria are efficiency of manufacturing, service and support, delivery, quality and assurance and new product. This result has concluded the way of improvement and demonstrates the sequences of amelioration on excellence manufacturing operation.

\subsection{Suggestions}

The foundries are moving full-speed ahead. This is one of the most important times in Foundry's history of electronic industry. Foundries have emerged from a challenging period in the previous decade and become much stronger today because are more globally focused, restructured and streamlined, and more committed than ever to true innovation. 
Also, there are some issues have been mentioned: (1) customers: treating customers as partners and have never competed against them. It is the key to current success and be crucial to the continued growth; (2) quality: building quality into all aspects of foundry business, every employee is responsible for providing the highest quality service. To achieve this, each person continuously evaluates and improves the quality of his/her own work for achieving and maintaining complete customer satisfaction; (3) long-term vision and strategies, an enterprise whose success endures is tough; that a person or company does plan carefully for the future and do a good job of long term planning and execution for greatly reducing the need of crisis management.

\section{Summary}

Taiwan is well-positioned to take wafer foundry business on the important global leadership role. We now have the global resources in place and certainly have the technological capability; foundry has clearly established itself as a global market leader in many interrelated high-tech categories.

The transformation of business model from IDM to foundry has produced an impressive outcome of historical performance. Being the largest and most successful dedicated IC foundry in the world it is not easy to maintain this position. Therefore, it is necessary to put more resources into manufacturing facilities and capacity than nearly anyone else and continue to be the trusted source to a global collection of innovative and savvy businesses, large and small, who appreciate the steadily increasing manufacturing capacity and consistent volume production levels.

This study found that the top five improving strategies among the evaluated criteria are efficiency of manufacturing, service and support, delivery, quality and assurance and new product. This result has concluded the way of improvement and demonstrates the sequences of amelioration on excellence manufacturing operation.

\section{References}

Chang, S.H.; Pai, P.F.; Yuan, K.J.; Wang, B.C. and Li, R.K. (2003), "Heuristic PAC model for hybrid MTO and MTS production environment," International Journal of Production Economics, 85, 347-358.

Hsieh, Y.C., Lin, N.P. and Chiu, H.C. (2002), "Virtual factory and relationship marketing - a case study of a Taiwan semiconductor manufacturing company," International Journal of Information Management, 22, 109-126.

Saaty, T. L. (1980), The Analytic Hierarchy Process: Planning, Priority Setting, Resource Allocation, New York: McGraw-Hill.

Sterman, J.D. (2001), "System Dynamics modelling: tools for learning in a complex world," California Management Review, 43(4), 8-25.

Su, Y.H.; Guo, R.S. and Chang, S.C. (2005), "Virtual fab: an enabling framework and dynamic manufacturing service provision mechanism,” Information \& Management, 42, 329-348. 